\title{
Effects of Light Curing Modes and Resin Composites on Temperature Rise under Human Dentin: An in vitro Study
}

\author{
Ihsan HUBBEZOGLU ${ }^{1}$, Arife DOGAN², Orhan Murat DOGAN ${ }^{3}$, Giray BOLAYIR ${ }^{3}$ and Bulent BEK ${ }^{3}$ \\ ${ }^{1}$ Department of Endodontics, Faculty of Dentistry, Cumhuriyet University, Sivas, Turkey \\ ${ }^{2}$ Department of Prosthodontics, Faculty of Dentistry, Gazi University, Ankara, Turkey \\ ${ }^{3}$ Department of Prosthodontics, Faculty of Dentistry, Cumhuriyet University, Sivas, Turkey \\ Corresponding author, Arife DOGAN; E-mail: adogan@gazi.edu.tr
}

\begin{abstract}
The influence of three curing modes of a high-powered LED curing unit on temperature rise under 2-mm-thick dentin was investigated during the polymerization of resin composite samples of Admira, Filtek P60, Premise, Tetric Flow, Tetric Ceram, and Filtek Z250. Ninety standard specimens were prepared. The bonding agents and resin composites were cured with standard, pulse, or soft-start mode ( $\mathrm{n}=5$ for each curing mode). Temperature rise was measured using a type $\mathrm{L}$ thermocouple. Data were analyzed by two-way ANOVA and Tukey's test. Soft-start curing led to statistically higher temperature rises compared than the other two modes. The highest temperature rise was observed for Admira and Tetric Flow cured with soft-start mode. The lowest temperature rise was observed for Premise cured with pulse mode. However, temperature rise did not reach the critical value that can cause pulpal damage by virtue of a prominent safety feature of the high-powered LED LCU, which ensures that no excessive heat is produced by all the three curing modes.
\end{abstract}

Key words: Temperature rise, Composites, Polymerization

Received Nov 18, 2007: Accepted Feb 23, 2008

\section{INTRODUCTION}

An important milestone in the history of modern restorative dentistry is the development of lightcured resin composites for direct procedures ${ }^{11}$. The majority of them are based on conventional monomer systems such as 2,2-bis [4-(2-hydroxy-3-methacryloyloxy-propoxy)-phenyl] propane (Bis-GMA), urethaneethoxydimethacrylate (UEDMA), and triethylene glycol dimethacrylate (TEGDMA), with camphorquinone (CQ) typically as the photosensitizer for free radical polymerization ${ }^{2}$. These resin composites include inorganic fillers in varying degrees, of varying sizes and types. Recently, a new type of organic-inorganic hybrid dental material, known as Ormocers, was introduced as an alternative to conventional dental composites. It has been stated that the combination of organic-inorganic matrix and filler particles in high concentrations (up to 67\%) in ormocers provided an improvement in some mechanical and physical properties, thereby rendering them superior to those of conventional composites $^{3-5)}$.

An increase in demand for esthetic dental restorations has also led to a tandem increase in the use of light sources to photocure resin composites ${ }^{6}$. Whereas the output of first-generation LED LCUs is limited ${ }^{7}$, manufacturers have recently turned their attention to high-powered LED LCUs for the polymerization of dental resins. With a high-powered light source, more photons are available per given period of absorption by the photoinitiators. As a result, more CQ molecules are raised to an excited state. The excited CQ molecules then collide with amine molecules to form free radicals. The latter, in turn, react with the carbon-carbon double bond of a monomer molecule and initiate the polymerization process $^{8,9}$. These LED LCUs generally have higher power densities, thereby producing potentially higher thermal emissions and depths of cure ${ }^{9}$.

Regardless of the amount of infrared energy transmitted from the curing source, polymerization of resin composites always results in a temperature increase in the material caused by both the exothermic polymerization and the light energy absorbed during irradiation ${ }^{7,10,11-17)}$. When using highpowered LCUs, the issue of temperature increase is of particular interest. This is because the increased energy of these LCUs may also increase the potential of generating injurious temperatures in the pulp - especially when they are used in deep cavities with minimal remaining dentin thickness ${ }^{10,12}$. Moreover, the concept of total adhesive bonding precludes the use of a protective cement base or cavity lining, which also means a higher potential for thermal injury to the pulp ${ }^{12}$.

It has been stated that the released energy and maximum polymerization temperature depend on the curing mode and polymerization characteristics of the dental composite ${ }^{17)}$. Traditionally, continuous cure at constant irradiance is used for the polymerization of resin composites. However, Feilzer et al. ${ }^{18)}$ 
pointed out that the use of high-intensity curing light negatively affected the restoration-cavity interface. To solve this problem, several curing protocols have been suggested. The so-called "soft-start polymerization" characterized by using an initial low-power intensity of the curing light followed by higher-power intensity has been suggested to minimize internal stresses in composites and improving their marginal adaptation ${ }^{11,19)}$. On the other hand, Kanca and Suh $^{20)}$ proposed "pulse-curing or pulse-delay curing". In this curing mode, the most occlusal increment of the resin composite is activated with a short pulse of light at rather low irradiance. They have shown that the use of this curing mode provided a reduction in enamel fractures and a general improvement of marginal adaptation, especially for Class I composite restorations when compared to those cured at constant irradiance.

However, few studies have been performed for the purpose of measuring temperature changes under the dentin in situations where the resin composites were cured with different curing protocols. When a high-powered LCU is used, it is important to determine the correct curing mode so as not to lead to a temperature rise which is potentially hazardous for the tooth. In light of this concern, the objective of this in vitro study was to evaluate the influence of different curing modes of a high-powered LED LCU on temperature rise under the dentin during the polymerization of six different composites.

\section{MATERIALS AND METHODS}

\section{Composites}

In this in vitro study, six different dental resin composites of shade A2 were tested for temperature rise. These composites were Admira (Voco GmbH, Cuxhaven, Germany), Filtek P60 (3M ESPE, St. Paul, MN, USA), Tetric Flow (Ivoclar Vivadent, Schaan, Liechtenstein), Tetric Ceram (Ivoclar Vivadent, Schaan, Liechtenstein), Filtek Z250 (3M ESPE, St. Paul, MN, USA), and Premise (Kerr Corp., Orange, CA, USA). The Admira composite is an ormocer consisting of additive aliphatic and aromatic dimethacrylates and Ba-Al-B-silicate glass and $\mathrm{SiO}_{2}$ inorganic filler particles loaded in $56 \%$ by volume. Filtek P60 is a packable resin composite and Filtek Z250 is a microhybrid resin composite, whereby both are based on Bis-GMA, urethane dimethacrylate (UDMA), and bisphenol A polyethylene glycol diether dimethacrylate (Bis-EMA) resin matrix. The filler is zirconia-silica and inorganic filler loading is $61 \%$ and $60 \%$ by volume for Filtek P60 and Filtek Z250 respectively. Tetric Flow is a flowable resin composite and Tetric Ceram is a microfilled hybrid resin composite, whereby both have similar resin matrices composed of Bis-GMA, UDMA, and
TEGDMA. Their inorganic fillers are composed of barium glass, ytterbium trifluoride, Ba-Al-fluorosilicate glass, highly dispersed silicone dioxide, and spheroid mixed oxide in $39.7 \%$ and $60 \%$ by volume for Tetric Flow and Tetric Ceram respectively. Premise is a nanofilled hybrid composite, which has an organic resin matrix composed of ethoxylated BisEMA and TEGDMA. Premise incorporates a trimodal filler system consisting of prepolymerized, barium glass, and silica nano fillers. The inorganic filler loading is $69 \%$ by volume.

The bonding systems recommended by each composite manufacturer were used. Three of them were total-etching single bottle systems (Admira Bond, Adper Single Bond 2, and Optibond Solo Plus), and the other was a self-etching adhesive system (AdheSE). Table 1 shows the detailed information of the resin composites and their manufacturers, as well as information on the conditioning system and bond matrix composition of each adhesive system.

\section{Light curing units}

The composites were cured with a high-powered LED LCU (Mini LED, Satelec, Merignac, France). Output of the LED unit stated by the LED manufacturer was accepted as accurate $\left(1100 \mathrm{~mW} / \mathrm{cm}^{2}\right)$, and five specimens of each composite were polymerized using one of the three curing protocols: standard (10-second exposure at full power), pulse mode (10 consecutive one-second exposures at full power), and soft-start mode (progressive cycle lasting 20 seconds). The energy produced by each polymerization mode was dependent on both the polymerization time and light intensity (total energy=light intensity $\times$ exposure time $)^{11,17,21-23)}$. In this study, total energy was $22 \mathrm{~J} /$ $\mathrm{cm}^{2}$ for soft-start polymerization, while it was $11 \mathrm{~J} /$ $\mathrm{cm}^{2}$ for the other two modes. The LED unit's battery was recharged according to manufacturer's recommendation and placed in its charger following the polymerization of each specimen. Table 2 shows the details pertaining to the LED unit and its polymerization modes and profiles.

\section{Preparation of dentin disks}

Ninety noncarious, extracted human premolars were stored in physiological saline solution in an incubator. The occlusal enamel portions of the premolars were removed using a low-speed saw (Isomet, Buehler Ltd., Lake Bluff, IL, USA) to expose the dentin by sectioning the tooth perpendicular to its long axis. Dentin disks, $2 \mathrm{~mm}$ thick, were then sectioned perpendicular to the long axis of the tooth, and 90 dentin disks were obtained as a result. These dentin disks were placed at the bottom of a Teflon mold cylinder of a temperature test apparatus as explained below. 
Table 1 Restorative materials used in this study

\begin{tabular}{|c|c|c|c|c|c|c|}
\hline Material & Admira & Filtek P60 & Tetric Flow & Tetric Ceram & Filtek Z250 & Premise \\
\hline Manufacturer & $\begin{array}{l}\text { Voco GmbH } \\
\text { Cuxhaven, } \\
\text { Germany }\end{array}$ & $\begin{array}{l}\text { 3M ESPE, St. } \\
\text { Paul, MN, USA }\end{array}$ & $\begin{array}{l}\text { Ivoclar Vivadent } \\
\text { Schaan / } \\
\text { Liechtenstein }\end{array}$ & $\begin{array}{l}\text { Ivoclar Vivadent } \\
\text { Schaan / } \\
\text { Liechtenstein }\end{array}$ & $\begin{array}{l}\text { 3M ESPE, St. } \\
\text { Paul MN, USA }\end{array}$ & $\begin{array}{l}\text { Kerr } \\
\text { Corporation, } \\
\text { Orange, CA, } \\
\text { USA }\end{array}$ \\
\hline Type & $\begin{array}{l}\text { Ormocer based } \\
\text { packable }\end{array}$ & $\begin{array}{l}\text { Composite-based } \\
\text { packable }\end{array}$ & $\begin{array}{l}\text { Composite-based } \\
\text { flowable }\end{array}$ & Hybrid & Microhybrid & $\begin{array}{l}\text { Nano-filled } \\
\text { hybrid }\end{array}$ \\
\hline Resin matrix & $\begin{array}{l}\text { Ormocers / } \\
\text { additive } \\
\text { aliphatic and } \\
\text { aromatic } \\
\text { dimethacrylates }\end{array}$ & $\begin{array}{l}\text { Bis-GMA, } \\
\text { UDMA } \\
\text { Bis-EMA }\end{array}$ & $\begin{array}{l}\text { Bis-GMA, } \\
\text { UDMA } \\
\text { TEGDMA }\end{array}$ & $\begin{array}{l}\text { Bis-GMA, } \\
\text { UDMA, } \\
\text { TEGDMA }\end{array}$ & $\begin{array}{l}\text { Bis-GMA, } \\
\text { UDMA } \\
\text { Bis-EMA }\end{array}$ & $\begin{array}{l}\text { ethoxylated } \\
\text { Bis-EMA, } \\
\text { TEGDMA }\end{array}$ \\
\hline Filler type & $\begin{array}{l}\text { Ba-Al-B-silicate } \\
\text { glass, } \mathrm{SiO}_{2}\end{array}$ & zirconia / silica & $\begin{array}{l}\text { barium glass, } \\
\text { ytterbium } \\
\text { trifluoride, Ba- } \\
\text { Al-fluorsilicate } \\
\text { glass, highlydis- } \\
\text { persed silicon } \\
\text { dioxide spheroid } \\
\text { mixed oxide }\end{array}$ & $\begin{array}{l}\text { barium glass, } \\
\text { ytterbium } \\
\text { trifluoride Ba- } \\
\text { Al-fluorsilicate } \\
\text { glass highly } \\
\text { dispersed silicon } \\
\text { dioxide spheroid } \\
\text { mixed oxide }\end{array}$ & zirconia / silica & $\begin{array}{l}\text { Barium glass, } \\
\text { non- } \\
\text { agglomerated } \\
\text { silica nano } \\
\text { particles, } \\
\text { prepolymerized } \\
\text { filler }\end{array}$ \\
\hline $\begin{array}{l}\text { Average particle } \\
\text { size }\end{array}$ & $0.7 \mu \mathrm{m}$ & $\begin{array}{l}0.01-3.5 \mu \mathrm{m} \\
\text { the mean } \\
\text { particle } 0.6 \mu \mathrm{m}\end{array}$ & $\begin{array}{l}0.04-3.0 \mu \mathrm{m} \\
\text { the mean } \\
\text { particle } 0.7 \mu \mathrm{m}\end{array}$ & $\begin{array}{l}0.04-3.0 \mu \mathrm{m} \\
\text { the mean } \\
\text { particle } 0.7 \mu \mathrm{m}\end{array}$ & $0.01-3.5 \mu \mathrm{m}$ & $\begin{array}{l}\text { barium glass: } \\
0.4 \mu \mathrm{m} \text {, silica } \\
\text { nano particles: } \\
0.02 \mu \mathrm{m}\end{array}$ \\
\hline Filler volume \% & 56 & 61 & 39.7 & 60 & 60 & 69 \\
\hline Filler weight \% & 78 & 80 & 64.6 & 79 & 82 & 84 \\
\hline $\begin{array}{l}\text { Co-initiators } \\
\text { absorption } \\
\text { within<410 nm }\end{array}$ & no & no & unknown & unknown & no & unknown \\
\hline $\begin{array}{l}\text { Bonding } \\
\text { Systems }\end{array}$ & Admira Bond & $\begin{array}{l}\text { Adper Single } \\
\text { Bond } 2\end{array}$ & AdheSE & & $\begin{array}{l}\text { Adper Single } \\
\text { Bond } 2\end{array}$ & $\begin{array}{l}\text { Optibond Solo } \\
\text { Plus }\end{array}$ \\
\hline Conditioning & $\begin{array}{l}\text { Vococid } \\
\text { ( } 35 \% \text { ortho- } \\
\text { phosphoric } \\
\text { acid gel) }\end{array}$ & $\begin{array}{l}\text { Scotchbond } \\
\text { etchant } \\
\text { (35\% phosphoric } \\
\text { acid gel) }\end{array}$ & \multicolumn{2}{|c|}{$\begin{array}{l}\text { AdheSE Primer: Dimethacrylate } \\
\text { phosphonic acid acrylate }\end{array}$} & $\begin{array}{l}\text { Scotchbond } \\
\text { etchant } \\
\text { (35\% phosphoric } \\
\text { acid gel) }\end{array}$ & $\begin{array}{l}\text { Kerr gel etchant } \\
(37.5 \% \\
\text { phosphoric acid } \\
\text { gel) }\end{array}$ \\
\hline Bond matrix & $\begin{array}{l}\text { Bis-GMA, } \\
\text { HEMA, organic } \\
\text { acids complex, } \\
\text { acetone three- } \\
\text { dimensionally } \\
\text { curing } \\
\text { anorganic- } \\
\text { organic } \\
\text { copolymers }\end{array}$ & $\begin{array}{l}\text { Bis-GMA, } \\
\text { HEMA, water } \\
\text { dimethacrylates, } \\
\text { ethanol } \\
\text { methacrylate } \\
\text { functional } \\
\text { copolymer of } \\
\text { polyacrylic and } \\
\text { polyitaconic } \\
\text { acids, silica } \\
\text { photoinitiators }\end{array}$ & \multicolumn{2}{|c|}{$\begin{array}{l}\text { AdheSE Bond: HEMA, } \\
\text { dimethacrylate silicone dioxide }\end{array}$} & $\begin{array}{l}\text { Bis-GMA, } \\
\text { HEMA, water } \\
\text { dimethacrylates, } \\
\text { ethanol } \\
\text { methacrylate } \\
\text { functional } \\
\text { copolymer of } \\
\text { polyacrylic and } \\
\text { polyitaconic } \\
\text { acid, silica } \\
\text { photoinitiators }\end{array}$ & $\begin{array}{l}\text { Bis-GMA, } \\
\text { HEMA, GPDM } \\
\text { ethanol, fumed } \\
\text { silica, barium, } \\
\text { sodium hexa- } \\
\text { fluorosilicate, } \\
\text { glass, } \\
\text { camphorquinone }\end{array}$ \\
\hline
\end{tabular}

*Data as disclosed by the manufacturers

Bis-GMA: Bisphenol A diglycidylmethacrylate; Bis-EMA: Bisphenol A polyethylene glycol diether dimethacrylate; UDMA: Urethane dimethacrylate;

TEGDMA: Triethyleneglycoldimethacrylate; HEMA: 2-Hydroxyethyl methacrylate; GPDM: Glycerophosphate dimethacrylate; GDM: Glycerol dimethacrylate 
Table 2 Details of the light polymerization unit and its polymerization modes and profiles

\begin{tabular}{|c|c|c|c|c|c|}
\hline Unit & $\begin{array}{l}\text { Light type } \\
\text { and diameter }\end{array}$ & $\begin{array}{l}\text { Wavelength } \\
\text { of emission }\end{array}$ & Mode & $\begin{array}{l}\text { Output and } \\
\text { total time }\end{array}$ & Profile \\
\hline \multirow[t]{3}{*}{ Mini LED } & $\begin{array}{l}\text { LED } \\
(7.5 \mathrm{~mm})\end{array}$ & 420-480nm & Standard & $\begin{array}{l}1100 \mathrm{~mW} / \mathrm{cm}^{2} \\
(10 \text { seconds })\end{array}$ & Continuous energy output for 10 seconds \\
\hline & & & Pulse & $\begin{array}{l}1100 \mathrm{~mW} / \mathrm{cm}^{2} \\
\text { (10 seconds) }\end{array}$ & $\begin{array}{l}10 \text { successive } 1 \text {-second flashes at full } \\
\text { power pulse activation mode, with a rest } \\
\text { period of } 250 \mathrm{~ms} \text { between flashes }\end{array}$ \\
\hline & & & Soft start & $\begin{array}{l}0 \text { to } 1100 \mathrm{~mW} / \mathrm{cm}^{2} \\
+1100 \mathrm{~mW} / \mathrm{cm}^{2} \\
\text { (20 seconds) }\end{array}$ & $\begin{array}{l}\text { Exponential energy output automatically } \\
\text { increased to full energy within } 10 \text { seconds } \\
+10 \text { seconds full energy }\end{array}$ \\
\hline
\end{tabular}

*Light intensity purported by manufacturer

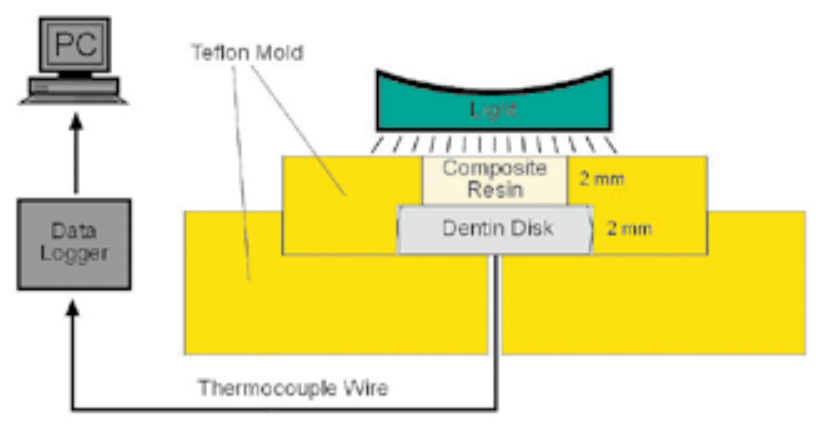

Fig. 1 Apparatus for measuring temperature changes.

\section{Temperature test apparatus}

To standardize temperature rise measurements, an apparatus was modified from that developed by Smail et al. ${ }^{24)}$ (Fig. 1). It comprised two concentric Teflon mold cylinders constructed from polyetrafluoroethylene. The top Teflon mold cylinder had a central aperture (6 $\mathrm{mm}$ diameter, $2 \mathrm{~mm}$ depth). The resin composite bulk was directly placed in this aperture onto the dentin disk treated with bonding agent. The bottom Teflon mold cylinder then formed the lateral walls of the dentin disk $(8 \mathrm{~mm}$ diameter, $2 \mathrm{~mm}$ depth). The bottom portion of the apparatus had a hole (1 mm diameter) just beneath the center of the dentin disk for thermocouple wire insertion. To achieve an accurate positioning of all the dentin disks, their thicknesses were standardized at $2 \mathrm{~mm}$ between the tip of the thermocouple and the resin composite in each experiment.

\section{Temperature measurement}

Fifteen specimens were prepared for each resin composite, whereby five specimens $(n=5)$ were polymerized using one of the three curing modes. All measurements were taken in a temperature- controlled room with a constant temperature of $20 \pm 1^{\circ} \mathrm{C}$. A type L Fe-constantan thermocouple (FeConst, Elimko Co., Turkey) connected to a data logger (E-680, Elimko Co., Turkey) was used to record temperature rise during the light-curing of bonding and resin composites. E-680 series of universal data loggers/scanners are advanced, newgeneration microcontroller-based industrial instruments compatible with IEC 668 standards. Universal inputs and outputs of the device could be programmed easily by the user, and data were collected and stored in a centrally located PC loaded with software (Data Logger, ver. 5.1, Elimko Co., Turkey).

Temperature rises were recorded at the following three levels:

1. Temperature rise beneath the dentin disk without any restoration to detect whether histochemical and/or structural variables of the dentin disk affected temperature change. Temperature rise beneath all dentin disks was effected by using LED LCU for 10 seconds. The mean temperature rise was $0.24 \pm 0.04^{\circ} \mathrm{C}$. Thus, it was concluded that the temperature change was not affected by any histochemical and/or structural dentin variables.

2. Temperature rise during polymerization of the visible light-cured bonding systems.

3. Temperature rise during polymerization of the resin composites. The central cylinder aperture was filled with the selected material and then covered with a Mylar strip and digitally pressed. For light curing, the LCU tip was positioned against the Teflon mold/ composite.

During each measurement, the initial temperature was recorded following temperature stabilization $\left(20 \pm 1^{\circ} \mathrm{C}\right)$ and then the peak temperature was registered. To obtain the temperature change, the initial temperature was deducted from the final 
one.

\section{Statistical analysis}

Using a SPSS statistical software program (Version 10.0, SPSS Inc., Chicago, USA), temperature change data were subjected to statistical analysis between the composites as well as among LED curing modes using two-way analysis of variance (ANOVA). Where significant differences were present, Tukey's post hoc test was applied to examine pairwise differences at a significance level of 0.05 .

\section{RESULTS}

Table 3 lists the means and standard deviations of temperature rise measured during the polymerization of six different composites with three different modes of LED LCU. Data analysis by two-way ANOVA showed significant temperature rise differences among the curing modes both during application of bonding agent $(\mathrm{F}=18.84)$ and polymerization of resin composites $(\mathrm{F}=119.54)$.
During the application of all bonding systems, the highest temperature rise was observed with the soft-start mode and this increase was statistically different from the other two modes $(p<0.05)$. Temperature rises observed with the standard- and pulse-mode curing of the bonding systems showed no statistical differences $(p>0.05)$. Admira and Tetric Flow resin composites showed the highest temperature increase when they were cured with soft-start mode $\left(1.50 \pm 0.11^{\circ} \mathrm{C}\right.$ and $1.46 \pm 0.05^{\circ} \mathrm{C}$ respectively), whereas pulse-mode curing of Premise resin composite led to the lowest temperature increase among the materials and curing modes tested $\left(0.22 \pm 0.04^{\circ} \mathrm{C}\right)$.

With soft-start curing, significantly higher temperature increase was recorded for Admira, Filtek P60, Tetric Ceram, and Premise resin composites as compared to the other two curing modes $(p<0.05)$. No statistically significant differences were observed for these specimens when they were cured with the standard and pulse modes $(p>0.05)$. For Tetric Flow and Filtek Z250 resin composites, temperature

Table 3 Mean temperature rise values and standard deviations (SD) for the resin composite systems and light curing modes evaluated

\begin{tabular}{|c|c|c|c|}
\hline Composite & Curing mode & $\begin{array}{l}\text { Bonding Agent Application } \\
\text { Mean } \pm \mathrm{SD}\end{array}$ & $\begin{array}{l}\text { Resin Composite Polymerization } \\
\text { Mean } \pm \text { SD }\end{array}$ \\
\hline \multirow[t]{3}{*}{ Admira } & Standard & $0.26 \pm 0.05$ & $0.54 \pm 0.11^{\mathrm{a}}$ \\
\hline & Pulse & $0.28 \pm 0.04$ & $0.42 \pm 0.08^{\mathrm{h}}$ \\
\hline & Soft start & $0.46 \pm 0.05^{*}$ & $1.50 \pm 0.07^{*, \mathrm{i}, \mathrm{j}, \mathrm{k}, \mathrm{l}}$ \\
\hline \multirow[t]{3}{*}{ Filtek P60 } & Standard & $0.24 \pm 0.05$ & $0.38 \pm 0.08^{\mathrm{d}, \mathrm{e}}$ \\
\hline & Pulse & $0.22 \pm 0.04$ & $0.34 \pm 0.05$ \\
\hline & Soft start & $0.46 \pm 0.05^{*}$ & $0.90 \pm 0.10^{*, \mathrm{i}, \mathrm{m}}$ \\
\hline \multirow[t]{3}{*}{ Tetric Flow } & Standard & $0.26 \pm 0.05$ & $0.62 \pm 0.08^{\mathrm{b}, \mathrm{d}, \mathrm{f}}$ \\
\hline & Pulse & $0.28 \pm 0.04$ & $0.38 \pm 0.04$ \\
\hline & Soft start & $0.46 \pm 0.05^{*}$ & $1.46 \pm 0.05^{*, \mathrm{~m}, \mathrm{n}, \mathrm{o}, \mathrm{p}}$ \\
\hline \multirow[t]{3}{*}{ Tetric Ceram } & Standard & $0.26 \pm 0.05$ & $0.40 \pm 0.07^{\mathrm{f}, \mathrm{g}}$ \\
\hline & Pulse & $0.28 \pm 0.04$ & $0.30 \pm 0.07$ \\
\hline & Soft start & $0.46 \pm 0.05^{*}$ & $1.08 \pm 0.13^{*, \mathrm{j}, \mathrm{r},}$ \\
\hline \multirow[t]{3}{*}{ Filtek Z 250} & Standard & $0.26 \pm 0.05$ & $0.62 \pm 0.08^{\mathrm{c}, \mathrm{e}, \mathrm{g}}$ \\
\hline & Pulse & $0.28 \pm 0.04$ & $0.24 \pm 0.05$ \\
\hline & Soft start & $0.46 \pm 0.05^{*}$ & $0.98 \pm 0.13^{*, \mathrm{k}, \mathrm{o}, \mathrm{s}}$ \\
\hline \multirow[t]{3}{*}{ Premise } & Standard & $0.24 \pm 0.05$ & $0.34 \pm 0.05^{\mathrm{a}, \mathrm{b}, \mathrm{c}}$ \\
\hline & Pulse & $0.22 \pm 0.04$ & $0.22 \pm 0.04^{\mathrm{h}}$ \\
\hline & Soft start & $0.46 \pm 0.05^{*}$ & $0.76 \pm 0.05^{*, \mathrm{l}, \mathrm{p}, \mathrm{r}, \mathrm{s}}$ \\
\hline
\end{tabular}

$\mathrm{n}=5$ specimens per experimental condition

By two-way ANOVA: $\mathrm{F}=18.84 \mathrm{P}=0.000 \quad \mathrm{p}<0.05$ for bonding agent application; $\mathrm{F}=119.54 \quad \mathrm{P}=0.000 \quad \mathrm{p}<0.05$ for resin composite polymerization.

Means labelled with the same small letters in the columns are for the comparison of different resin composites cured with the same light curing mode; ${ }^{*}$ :denotes the highest temperature rise values among three light curing modes of a given material. They are significantly different by Tukey's test $(\mathrm{p}<0.05)$. 
change with each of the three curing modes differed $(\mathrm{p}<0.05)$.

Tukey's test results showed that the standard mode curing led to statistically significant differences in temperature rise between Admira and Premise, Filtek P60 and Tetric Flow, Filtek P60 and Filtek Z250, Tetric Flow and Tetric Ceram, Tetric Flow and Premise, Tetric Ceram and Filtek Z250, and Premise and Filtek Z250 $(\mathrm{p}<0.05)$. Pulse-mode curing of composites did not lead to statistically different temperature variations among all the resin composites, except between Admira and Premise which were found to be statistically different from each other at $p<0.05$. The comparison of temperature changes of all resin composites cured with soft-start mode showed no statistically significant differences between Admira and Tetric Flow, Filtek P60 and Tetric Ceram, Filtek P60 and Filtek Z250, Filtek P60 and Premise, and Tetric Ceram and Filtek Z250 $(p>0.05)$; the others were found to be statistically different from each other $(p<0.05)$.

\section{DISCUSSION}

Temperature rise during polymerization is a consequence of both the exothermic reaction process and the radiant heat from the light curing unit. The contribution from the material depends on material composition, material depth, and ambient temperature, whereas contribution from the light depends on exposure time and characteristics of the light source ${ }^{14)}$. This in vitro study sought to evaluate the effect of three different polymerization modes of a latest high-powered LED LCU on temperature rise under human dentin during the polymerization of different resin composite systems. A stringently standardized dentin thickness ( $2 \mathrm{~mm}$ ) was used with a view to eliminating any possible variation in thermal transfer. Further, a composite specimen size of $2 \mathrm{~mm}$ thickness was selected as it was considered to be clinically realistic ${ }^{16)}$. Many manufacturers quote 2-mm-thick specimens when recommending radiation times. On the shade of resin composite specimens, shade A2 was selected to minimize the effects of colorant on light polymerization ${ }^{21}$.

Temperature increases up to $20^{\circ} \mathrm{C}$ have been measured during light-induced polymerization of composite resins ${ }^{19,25)}$. According to Zach and Cohen ${ }^{26)}$, a temperature rise of $5.5^{\circ} \mathrm{C}$ in the pulp is the limit that permits the pulp to recover from thermal damage. In the current study, temperature changes were measured during the operation of a highpowered LED LCU with a starting temperature of $20 \pm 1^{\circ} \mathrm{C}$ as previously suggested ${ }^{7,27)}$. Temperature increases under dentin were continuously measured up to the point where the temperature began to fall. The peak values registered during the curing of all the tested materials with each of the three modes were lower than this previously reported critical value. This below-critical-value temperature rise could be attributed to a prominent feature of this high-powered LED LCU, in that there was basically no infrared light transmission to the tooth - and hence no excessive heat was produced ${ }^{27}$. Based on the data obtained in this study, it may be suggested that this LED light source could be used safely in similar clinical situations.

Resin composites were used with their own bonding agents in order to simulate clinical use. The same curing mode made no statistically significant differences among the bonding agents, which was probably due to the same irradiation time. Ozturk et $a l{ }^{28)}$ have compared the temperature changes under 1-mm-thick dentin using total-etch and self-etch adhesive systems and polymerization using a LED LCU. They obtained a higher temperature rise $\left(1.61^{\circ} \mathrm{C}\right)$ for both types of adhesives systems than those found in the current study. The use of different dentin thicknesses might explain this. Knezevic et $a l{ }^{29)}$ have reported higher temperature increases with increased irradiation time and decreased material thickness. During the application of all the bonding systems in this study, the highest temperature rise was observed with the soft-start mode of LED LCU at a value of $0.46 \pm 0.05^{\circ} \mathrm{C}$. The reason for this result could stem from the irradiation time of soft-start mode being approximately two times longer than the other curing modes. Furthermore, the absence of remarkable temperature changes in this study supported the suggestion by Shortall and Harrington ${ }^{16)}$ that greater thermal insult might occur when polymerizing bonding resins prior to restorative resins.

The soft-start mode was introduced to reduce shrinkage stress of dental composites, to achieve smaller marginal gaps, and to increase marginal integrity $^{30-32)}$. However this technique requires long cure times and consequently increases the energy produced, raising the temperature of resin composites and the surrounding dentin ${ }^{11}$. In the current study, the temperature rise induced by each curing mode did not exceed a previously reported critical value. In this respect, the thermal insulation provided by a relatively thick dentin ${ }^{7)}$ might be effective. However, in deep cavities where the residual dentin thickness is smaller and the tubular surface area increase ${ }^{17}$, soft-start mode should be used cautiously to avoid excessively heating the pulp. This is because during the polymerization of all the tested resin composites, the highest temperature increase under dentin was consistently recorded with soft-start mode. Conversely, the pulse mode yielded the lowest temperature rise for all the tested resin composites.

These data were in agreement with those of 
Aguiar et $a l .{ }^{11)}$, who evaluated the effect of five polymerization modes and the presence of resin composite on temperature rise in human dentin of different thicknesses. They found that conventional and high-intensity polymerization modes presented lower temperature rise than soft-start mode in all conditions. However, the values obtained were higher than those of the current study, which could be due to the test conditions and light source used. According to Loney and Price ${ }^{33)}$, the difference in energy produced by the light curing units was an important factor for different temperature rises in different polymerization modes. Therefore, the differences in energy produced by the three curing modes might be responsible for the differences in the observed temperature changes.

With regard to material composition, Shortall and Harrington ${ }^{16)}$ have concluded that temperature rise is also related to the light transmission characteristics of resin composition. Masutani et al. ${ }^{34)}$ suggested that the exothermic reaction of the resin during polymerization had a greater influence on temperature rise vis-à-vis the light source. This suggestion was supported by our results where the temperature rise was very specific to a given composite due to its unique combination of filler, resin characteristics and formulation. While the highest temperature increase was observed for ormocer (Admira) and flowable (Tetric Flow) resin composites with soft-start curing, the lowest temperature rise was observed for nanofilled hybrid resin material (Premise) with pulse curing. It should be highlighted that all the composites tested had different volume fractions of the organic resin matrix. This appeared to be effective in influencing the extent of exothermic reaction during the polymerization process, and thus the differences in temperature change.

Under the same light-curing conditions, the different thermal conductivity values of composites and the different patterns of energy density distribution along time ${ }^{27}$ ) could help explain the results in this study. The ormocer material possessed a modified organic matrix, formed by monomers with a single polymerizable end. The other end was formed by an alkoxy group, resulting in an inorganic area, bonded to other monomers by a chemical reaction of condensation, converting the monomer precursors in a polymeric inorganic condensate - via sol-gel processing - to create a complex structure with the formation of the Si-O-Si chain in the inorganic area of the polymer ${ }^{3-5,35)}$. The significantly greater temperature rise with the ormocer compared to the other products presumably resulted from the different monomer compositions, given the relatively low light transmittance of this product.

Although Filtek Z250 and Filtek P60, and Tetric
Ceram and Tetric Flow had the same molecules in their organic matrices and the same types of fillers, they showed different temperature rises. According to the data given by the manufacturers, the majority of TEGDMA was replaced with a blend of UDMA and BisEMA in Filtek Z250 when compared to Filtek P60. On the other hand, Tetric Ceram had a higher amount of inorganic filler than Tetric Flow. Taking these differences into consideration, they could have thus led to a decrease in temperature rise during polymerization. Tarle et $a l .^{36)}$ found higher temperature rises with standard-mode curing of hybrid composite Tetric Ceram $\left(2.2^{\circ} \mathrm{C}\right)$ and microhybrid composite Filtek Z250 $\left(1.5^{\circ} \mathrm{C}\right)$ than those found in the current study for the same materials $\left(0.40^{\circ} \mathrm{C}\right.$ and $0.62^{\circ} \mathrm{C}$ respectively). It should be highlighted that in their experiment ${ }^{36)}$, they used one of the early commercial blue LED LCUs giving an exposure profile of 10 seconds at $50 \mathrm{~mW} / \mathrm{cm}^{2}$, then 30 seconds at $150 \mathrm{~mW} / \mathrm{cm}^{2}$. Differences in the curing protocol might help to explain the differences in results between the two studies using the same products.

Premise, which is a nanofilled resin composite, has been highly rated for handling, polishability, esthetics, and shade matching by clinical evaluators ${ }^{37)}$. Its manufacturer claimed that this resin demonstrated only moderate polymerization shrinkage caused by changes in dimensions as the resin was being cured. The temperature measurements under all conditions revealed the lowest temperature rise with this product and affirmed its safe use in clinical situations.

In this study, final temperature increases during polymerization with the high-powered LED LCU appeared to be below the critical value that can cause pulpal damage, thereby indicating its safety. In the current study, temperature change was evaluated under human dentin of $2 \mathrm{~mm}$ thickness. At this juncture, it should be put into perspective that for heat-related pulpal injury, the remaining dentin thickness is a critical factor that influences the amount of heat reaching the pulp. Therefore, further studies should be performed to confirm the effects of different curing modes on temperature change during the polymerization of composites placed over a thinner dentin. This would then mimic a more realistic clinical situation.

\section{CONCLUSIONS}

Within the limitations of this in vitro study, the following conclusions were drawn:

(1) The high-powered LED LCU caused minimal temperature rise under dentin during the polymerization of all resin composite systems.

(2) Soft-start curing led to significantly higher 
temperature increases under dentin than the standard and pulse modes.

(3) Temperature rise was found to be materialdependent. The differences were found to be statistically significant among all the materials tested.

(4) Highest temperature rise was observed for the soft-start curing of Admira and Tetric Flow.

(5) Pulse curing of Premise gave the lowest temperature rise among the materials tested.

\section{ACKNOWLEDGEMENTS}

Special thanks go to Assoc. Professor Ali Fazl Yenidünya, Cumhuriyet University, Faculty of Science and Arts, Department of Biology, for his invaluable contribution in the preparation of this manuscript for submission.

This work was supported by CUBAP, Project Nr. DIS-043.

\section{REFERENCES}

1) Aguiar FHB, Bracairo A, Lima DANL, Ambrosano GMB, Lovadino JR. Effect of light curing modes and light curing time on the microhardness of a hybrid composite resin. J Contemp Dent Pract 2007; 8: 1-8.

2) Kleverlaan CJ, de Gee AJ. Curing efficiency and heat generation of various resin composites cured with high-intensity halogen lights. Eur J Oral Sci 2004; 112: 84-88.

3) Cunha LG, Alonso RCB, dos Santos PH, Sinhoretti MAC. Comparative study of the surface roughness of ormocer-based and conventional composites. J Appl Oral Sci 2003; 11: 348-353.

4) Papadogiannis Y, Lakes RS, Palaghias G, Helvatjoglu-Antoniades M, Papadogiannis D. Fatigue of packable dental composites. Dent Mater 2007; 23: 235-242.

5) Wolter H. Bulk-ORMOCERs and ORMOCER composites. Fraunhofer-Institut für Silicatforschung (ISC)-Annual Report 1995; 45-51.

6) Wataha JC, Lockwood PE, Lewis JB, Rueggeberg FA, Messer RLW. Biological effects of blue light from dental curing units. Dent Mater 2004; 20: 150157.

7) Schneider LFJ, Consani S, Sinhoreti MAC, Sobrinho LC, Milan FM. Temperature change and hardness with different resin composites and photo-activation methods. Oper Dent 2005; 30: 516-521.

8) Moon HJ, Lee YK, Lim BS, Kim CW. Effects of various light curing methods on the leachability of uncured substances and hardness of a composite resin. J Oral Rehabil 2004; 31: 258-264.

9) Wandewalle KS, Roberts HW, Tiba A, Charlton DG. Thermal emission and curing efficiency of LED and halogen curing lights. Oper Dent 2005; 30: 257-264.

10) Bouilllguet S, Caillot G, Forchelet J, Cattani-Lorente M, Wataha JC, Krejci I. Thermal risks from LEDand high-intensity QTH-curing units during polymerization of dental resins. J Biomed Mater
Res Part B: Appl Biomater 2005; 72B: 260-267.

11) Aguiar FHB, Barros GKP, dos Santos AJ, Ambrosano GMB, Lovadino JR. Effect of polymerization modes and resin composite on the temperature rise of human dentin of different thicknesses: An in vitro study. Oper Dent 2005; 30: 602-607.

12) Danesh G, Davids H, Duda S, Kaup M, Ott K, Schafer E. Temperature rise in the pulp chamber induced by a conventional halogen light-curing source and a plasma arc lamp. Am J Dent 2004; 17: 203-208.

13) Hannig M, Bott B. In-vitro pulp chamber temperature rise during composite resin polymerization with various light-curing sources. Dent Mater 1999; 15: 275-281.

14) McAndrew R, Lloyd $\mathrm{CH}$. The effect of a cement lining upon the temperature rise during the curing of composite by visible light. J Dent 1987; 15: 218221.

15) Al-Qudah AA, Mitchell CA, Biagioni PA, Hussey DL. Effect of composite shade, increment thickness and curing light on temperature rise during photocuring. J Dent 2007; 35: 238-245.

16) Shortall AC, Harrington E. Temperature rise during polymerization of light-activated resin composites. J Oral Rehabil 1998; 25: 908-913.

17) Uhl A, Völpel A, Sigush BW. Influence of heat from light curing units and dental composite polymerization on cells in vitro. J J Dent 2006; 34: 298-306.

18) Feilzer AJ, Dooren LH, de Gee AJ, Davidson CL. Influence of light intensity on polymerization shrinkage and integrity of restoration-cavity interface. Eur J Oral Sci 1995; 103: 322-326.

19) Hoffmann N, Hugo B, Klaiber B. Effect of irradiation type (LED or QTH) on photo-activated composite shrinkage strain kinetics, temperature rise, and hardness. Eur J Oral Sci 2002; 110: 471479 .

20) Kanca J, Suh. BI. Pulse activation: reducing resinbased composite contraction stresses at the enamel cavosurface margins. Am J Dent 1999; 12: 107-112.

21) Uhl A, Mills RW, Jandt KD. Polymerization and light-induced heat of dental composites cured with LED and halogen technology. Biomaterials 2003; 24: $1809-1820$.

22) Lovell LG, Newman SM, Donaldson MM, Bowman CN. The effect of light intensity on double bond conversion and flexural strength of a model, unfilled dental resin. Dent Mater 2003; 19: 458-465.

23) Yap AUJ, Wong NY, Siow KS. Composite cure and shrinkage associated with high intensity cuing light. Oper Dent 2000; 25: 98-103.

24) Smail SRJ, Patterson CJW, McLundie AC, Strang R. In vitro temperature rises during visible light curing of a lining material and a posterior composite. J Oral Rehabil 1988; 15: 361-366.

25) Knezevic A, Tarle Z, Meniga A, Sutalo J, Pichler G, Ristic M. Degree of conversion and temperature rise during polymerization of composite resin samples with blue diodes. J Oral Rehabil 2001; 28: 586-591.

26) Zach L, Cohen G. Pulp response to externally applied heat. Oral Surg Oral Med Oral Pathol 1965; 19: 515-530.

27) Schneider LFJ, Consani S, Correr-Sobrinho L, 
Correr AB, Sinhoreti MA. Halogen and LED light curing of composite: Temperature increase and Knoop hardness. Clin Oral Invest 2006; 10: 66-71.

28) Ozturk B, Ozturk AN, Usumez A, Usumez S, Ozer F. Temperature rise during adhesive and resin composite polymerization with various light curing sources. Oper Dent 2004; 29: 325-332.

29) Knezevic A, Tarle Z, Meniga A, Sutalo J, Pichler G, Ristic M. Photopolymerization of composite resins with plasma light. J Oral Rehabil 2002; 29: 782786.

30) Davidson CL, Feilzer AJ. Polymerization shrinkage and polymerization shrinkage stress in polymerbased restoratives. J Dent Res 1997; 25: 435-440.

31) Uno S, Asmussen E. Marginal adaption of a restorative resin polymerized at reduced rate. Scand J Dent Res 1991; 99: 440-444.

32) Goracci G, Casa De Martins L, Mori GF. Curing light intensity and marginal leakage of composite resin restorations. Quintessence Int 1996; 27: 355362 .
33) Loney RW, Price RB. Temperature transmission of high-output light-curing units through dentin. Oper Dent 2001; 26: 516-520.

34) Masutani S, Setcos JC, Schnell RJ, Phillips RW. Temperature rise during polymerization of visible light-activated composite resins. Dent Mater 1988; 4: 174-177.

35) Hubbezoglu I, Akaoglu B, Dogan A, Keskin S, Bolayir G, Ozcelik S, Dogan OM. Effect of bleaching on color change and refractive index of dental composite resins. Dent Mater J 2008; 27: 105-116

36) Tarle Z, Knezevic A, Demoli N, Meniga A, Sutalo J, Unterbrink G, Ristic M, Pichler G. Comparison of composite curing parameters: Effects of light source and curing mode on conversion, temperature rise and polymerization shrinkage. Oper Dent 2006; 31 : 219-226.

37) Terry DA. Direct applications of a nanocomposite resin system: Part 1 - The evolution of contemporary composite materials. Pract Proced Aesthet Dent 2004; 16: 417-422. 